\title{
DISCOURSE MARKERS IN THE SEPTUAGINT AND EARLY KOINE GREEK WITH SPECIAL REFERENCE TO THE TWELVE ${ }^{1}$
}

\author{
Christopher James Fresch \\ (fresch@biblecollege.sa.edu.au)
}

Discourse markers (e.g. $\delta \dot{\varepsilon}, \dot{\alpha} \lambda \lambda \dot{\alpha})$ comprise a functional category. They narrow or explicate discourse relations, instructing the reader on how to process the discourse and build a mental representation of it. In so doing, they aid the reader in the comprehension task, reducing cognitive effort and facilitating successful communication. Unfortunately, these considerations rarely feature in discussions on Greek discourse markers. Instead, their functions are often conflated with the semantics of their surrounding contexts of use and with the functions of their translational glosses. This often results in less precision in one's comprehension of the flow and structure of the discourse.

The aim of this thesis is twofold. First, it examines a selection of

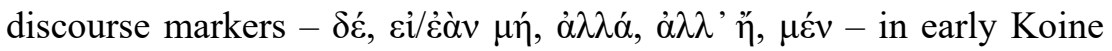
Greek from a cognitive-functional linguistic framework in order to determine their pragmatic functions. Each chapter begins with an investigation of a discourse marker in the Ptolemaic papyri, thus providing a basic map of the marker's function(s) in early Koine. This is followed by a treatment of its occurrences in the Old Greek text of the Minor Prophets, or, if more data are required, its occurrences throughout the Greek Pentateuch or the entire Greek Old Testament. Thus, for each discourse marker, a profile is built of its pragmatic function(s) based on its uses in the Ptolemaic papyri and the Greek Old Testament. In addition to the Greek language data, insights and data from cognitive, functional, and typological linguistics are incorporated that inform and further confirm the findings. The resulting profile is

1 Christopher James Fresch (Ph.D. dissertation, University of Cambridge, 2015). Supervisor Dr James K. Aitken. 
then compared to descriptions of the discourse marker in Classical Greek and Koine (typically New Testament) Greek studies. This has the benefit of illustrating the similarities between the cognitivefunctional profiles and more traditional descriptions of the discourse markers whilst also demonstrating the usefulness of the cognitivefunctional linguistic framework and the precision and clarity it provides.

To this end, for example, $\delta \varepsilon$ is described as a marker that organises and structures the discourse by signalling the beginning or (less typically) the end of a distinct information unit. It often segments material that corresponds with a new development within the discourse, such as a new scene or topic to be discussed. This description differs considerably from the traditional conception of $\delta \dot{\varepsilon}$ as an adversative marker, but it finds overwhelming support in the Ptolemaic papyri, where $\delta \dot{\varepsilon}$ is used to signal the structure of the letter proper or to segment thematic units, and in the Greek Book of the Twelve, where $\delta \varepsilon$ breaks up the discourse into smaller pieces, such as by introducing new narrative scenes (e.g. Jon. 3:3) or the next step of an argument (e.g. Jon. 4:11). The function that is observed in $\delta \varepsilon$ can be oberserved crosslinguistically. Segmenting distinct units of discourse is a common (and arguably necessary) feature of language, whether by means of a discourse marker or by some other method, that faciliates successful communication by breaking up a discourse into smaller, more cognitively manageable units. Biblical Hebrew, for example, often interrupts a wayyiqtol chain in contexts of discontinuity, where the sentence topic is switched or there is a movement to a new scene, by beginning the next sentence with a nominal constituent. Such stark breaks segment the discourse and provide the reader with cognitive breathing space. As one may expect, in the Greek Minor Prophets, $\delta \varepsilon$ often appears where the Hebrew text exhibits such a break.

Another example is $\dot{\alpha} \lambda \lambda^{\prime} \eta^{\prime}$, which has not been the subject of much linguistic investigation. It is determined that $\dot{\alpha} \lambda \lambda \lambda^{\prime} \ddot{\eta}$ signals an exclusive corrective relation. The discourse marker is similar to $\alpha \lambda \lambda \dot{\alpha}$, given that it signals what follows as a corrective to some element within the recipient's mental representation of the discourse, but it differs by narrowing the reader's focus to the salient exclusive or limited element of the corrective (similar to English's 'but only'). This description of the marker is able to account for its occurrences in the papyri and the Greek Old Testament, and it provides a clearer picture 
than other descriptions as to what an author or translator is attempting to communicate by using $\dot{\alpha} \lambda \lambda^{\prime} \eta^{\prime}$.

The second aim of the thesis is to investigate how the occurrences of these discourse markers in the Greek Old Testament correspond to the underlying Hebrew. Because the functional aspects of discourse markers are rarely considered, their significance to the study of Septuagint translation technique is often overlooked. However, owing to their very nature, the use of discourse markers in the Greek Old Testament demonstrates, at the least, an awareness of the linguistic context on the part of the translators. That is to say, in order to use discourse markers idiomatically, it would have often required the translator to have not only some conception of the flow of the discourse prior to the marker, but after as well. Moreover, few of these Greek discourse markers have lexical equivalents in Hebrew. Thus, their occurrences often evince translators who were willing to render into natural Greek idiom despite lacking clear lexical motivation in their source texts. Such uses provide further indication of how the translators understood and conceived of the structure and flow of the discourse as well as their desire to render their source texts idiomatically. This is especially significant in those cases where the Hebrew text does not explicitly signal the same discourse structure or is structured differently. This has the resulting effect of further informing the study of Septuagint translation technique generally, given its tendency to focus on lexical semantics and syntax but not discourse structure, as well as providing a complementary point of investigation into a given translator.

A result of this line of investigation is that a picture is painted of the translator(s) of the Greek Minor Prophets in particular that evinces clear ability in Greek and Hebrew and in translation beyond mere lexical representation. Despite the fact that most of the Greek discourse markers investigated do not have lexical equivalents in Hebrew, and despite two of them being postpositives (thus resulting in an altered word order vis-à-vis the Hebrew Vorlage), the translator(s) chose to use them. Their occurrences never feel out of place or rhetorically motivated; rather, their use indicates a contextual awarenss and the intent to produce a text that is idiomatic and that conveys meaning on a pragmatic level, thereby guiding the reader in the comprehension process. Furthermore, the use of these discourse markers demonstrates the desire to faithfully render the source text, even if that requires 
foregoing lexical representation. Though the discourse markers often do not literally represent the Hebrew, they do convey the meaning of it.

Such insights into Septuagint translators challenge assumptions held in Septuagint scholarship. A common claim in Septuagint scholarship is that the Septuagint translators had no awareness of context (even the most immediate context) as they translated. This thesis counters such a view by demonstrating that the choice to use a discourse marker that is not lexically motivated is necessarily informed by an awareness of context and the structure of the discourse. Especially, given the natural uses of the discourse markers and their suitability to their contexts, they often serve as clear indicators of a translator's understanding of the wider discourse. By challenging the widely held view, the thesis provides an altered starting point for thinking about the Septuagint translators and how they went about their task.

Another result of the thesis with regard to the language of the Greek translations of the Old Testament is that it further confirms the genuine Koine idiom in which the translations were written. It is demonstrated that there is essentially no difference between how the discourse markers are used in the Ptolemaic papyri and how they are used in the Greek Old Testament. Thus the consistent usage of these discourse markers in the Greek Old Testament reflects Greek idiom of the day.

In sum, given the above two aims, the thesis seeks to provide a fuller and more precise understanding of Greek discourse markers to illustrate the value of linguistic enquiry that is informed by modern linguistic frameworks and to demonstrate the usefulness of such enquiry to the study of Septuagint translation technique. It is shown that descriptions of Greek discourse markers benefit from a cognitivefunctional framework, which also has the advantage of placing the discourse markers in the broader context of how humans use various pragmatic features of language to structure discourse in order to facilitate communication and ease cognitive processing. Using these descriptions, the thesis demonstrates that such an analysis of Greek discourse markers contributes to the study of Septuagint translation technique, providing a fuller understanding of how the translators engaged with and rendered their Vorlagen. 